Proceedings of SALT 22: 268-285, 2012

\title{
Contrastive topics in Paraguayan Guaraní discourse*
}

\author{
Judith Tonhauser \\ The Ohio State University
}

\begin{abstract}
The empirical basis of current formal semantic/pragmatic analyses of utterances containing contrastive topics are languages in which the expression that denotes the contrastive topic is marked prosodically, morphologically or syntactically, such as English, German, Korean, Japanese or Hungarian (e.g. Jackendoff 1972; Szabolcsi 1981; Roberts 1998; Büring 1997, 2003; Lee 1999). Such analyses do not extend to Paraguayan Guaraní, a language in which neither prosody, nor word order, nor the contrastive topic clitic =katu identify the contrastive topic. This article develops a formal pragmatic analysis of contrastive topic utterances in Paraguayan Guaraní and explores cross-linguistic similarities and differences in contrastive topic utterances.
\end{abstract}

Keywords: Contrastive topic, Paraguayan Guaraní, cross-linguistic variation.

\section{Introduction}

Natural language discourse is generally assumed to be organized around conversational goals that are mutually agreed upon by the discourse participants and fulfilled through question and answer moves (e.g. Ginzburg 1995; Roberts 1998). Particularly clear insight into the structure and organization of discourse is afforded by prosody and discourse particles that impose constraints on discourse (see e.g. Rooth 1992; Zimmermann 2011). English utterances realized with contrastive topic prosody have received particular attention in the formal semantic/pragmatic literature on discourse structure (e.g. Jackendoff 1972; Roberts 1998; Büring 1997, 2003). For example, R's utterance in (1), which is based on Jackendoff 1972: 261, can be prosodically realized with a complex accent pattern consisting of a fall+rise on Fred (Jackendoff's 1972 'B accent') and a falling accent on beans (Jackendoff's 'A accent').

* For helpful comments and discussion I thank Cynthia Clopper, Noah Constant and Craige Roberts, as well as audiences at The Ohio State University and at SALT XXII. I also thank my Paraguayan Guaraní consultants: Alissio Arce Doldan, Mario Ayala Esteche, Marité Maldonado, Evert Ojeda Morán, Julio Rolon, and the late Teresa Bogado. This project was financially supported by a research grant from the National Science Foundation to David Beaver, Craige Roberts, Mandy Simons and Judith Tonhauser ('Collaborative Research: Semantics and Pragmatics of Projective Meaning across Languages'; grants BCS-0952571, BCS-0952497, BCS-0952862.) 
(1) Context: $\mathrm{S}$ and $\mathrm{T}$ are quizzing $\mathrm{R}$ about a dinner party $\mathrm{R}$ attended.

S: Who ate what?

T: What about FRED? What did HE eat?

R: FRED $_{\text {fall }+ \text { rise }}$ ate the BEANS $_{\text {fall }}$.

The constituent marked with the fall+rise accent, Fred in (1R), is typically referred to as the contrastive topic, whereas the constituent marked with the falling accent, beans in (1R), is the focus, the answer to T's immediately preceding question under discussion. Realized with this accent pattern, R's utterance contrasts Fred with others that attended the party and suggests that they ate things other than beans.

$\mathrm{R}$ 's utterance in (2) is string-identical to R's utterance in (1), but the differences in accent placement indicate that this utterance is part of a discourse in which beans are contrasted with other things eaten at the party.

(2) Context: $\mathrm{S}$ and $\mathrm{T}$ are quizzing $\mathrm{R}$ about a dinner party $\mathrm{R}$ attended.

S: Who ate what?

T: What about the BEANS? Who ate THEM?

R: FRED $_{\text {fall }}$ ate the BEANS fall + rise $_{\text {. }}$

Since R's utterance in (1) is unacceptable in the context of (2), and vice versa, it is generally assumed that these two accent patterns "are conventionally associated with different interpretations, in particular, different appropriateness conditions" (Büring 2003: 512).

This article explores contrastive topic utterances in Paraguayan Guaraní, a TupíGuaraní language spoken in Paraguay and surrounding countries. In this language, such utterances are marked with the clitic $=k a t u$, glossed '=CONTRAST'. In (3), for example, the duck, who is bothered, is contrasted with the frog, who is unhappy. ${ }^{1}$

(3) [From a fable about a frog and a duck.] 'The frog was very unhappy...

ha ypé=katu iñ-angekói hese.

and duck=CONTRAST B3-bother by.him

'and the duck was bothered by him.'

1 The Paraguayan Guaraní examples are given in the standardized orthography of the language used in Paraguay (Ministerio de Educación y Cultura 2004, Velázquez-Castillo 2004: 1421f.), except that all postpositions are attached to their host. Following this orthography, stressed oral syllables are marked with an acute accent and stressed nasal syllables are marked with a tilde; acute accents are not written for normally accented words (stress on the final syllable). The following glosses are used: A/B 1/2/3 = set A/B 1st, 2nd, 3rd person crossreference marker, CAUS = causative, CONTRAST $=$ contrastive topic, $\mathrm{COP}=$ copula, $\mathrm{EMPH}=$ emphatic, $\mathrm{NEG}=$ negation, pron $=$ pronoun, $\mathrm{PROSP}=$ prospective aspect/modal, $\mathrm{SAY}=$ reportative evidential, $\mathrm{QU}=$ question. ' $\mathrm{K}$ et al. 2005 ' abbreviates Krivoshein de Canese, Martinez Gamba \& Acosta Alcaraz 2005. 
This article first empirically motivates that $=k a t u$ marks utterances as containing a contrastive topic, and then turns to illustrating differences between =katu and contrastive topic markers in other languages. In particular, contrastive topic utterances in Paraguayan Guaraní (henceforth, Guaraní) differ from such utterances in other languages in that the expression that constitutes the contrastive topic is not grammatically marked in Guaraní, whereas it is generally taken to be marked by prosodic, morphological or syntactic means in other languages, including English, German, Korean, Japanese and Hungarian (e.g. Jackendoff 1972; Szabolcsi 1981; Kiss 1987; Roberts 1998; Büring 1997, 2003; Lee 1999). Since research on the structure of discourse is limited for the most part to well-studied European and East Asian languages, little is known about cross-linguistic universals and variation in structuring discourse (see also von Fintel \& Matthewson 2008). The formal pragmatic analysis of utterances with $=k a t u$ developed in this article thus also serves to provide insight into the structure of discourse in Guaraní.

\section{The elusive and ineffable meaning of katu}

In semantic fieldwork, translations offered by language consultants can often provide important clues for the development of hypotheses about the meanings of expressions. This strategy did not prove feasible in the case of Guaraní katu since consultants either found themselves unable to offer a translation or offered distinct translations for different occurrences of the expression. Dictionaries and grammars also gave a range of translations, such as German aber 'but' (Bossong 1983: 40) or the discourse particles halt, doch (Lustig 1996), English indeed, certainly (Gregores \& Suárez 1967: 229), good or a little (Guasch \& Ortiz 2001: 601), and katu was said to be "used in imperatives" or "to signify custom or repetition" (ibid).

A corpus study of the expression katu finally led to a working hypothesis and also offered some insight into why katu has been given such a plethora of translations. The corpus used to study katu contained over 26,000 Guaraní words (which corresponds to about 100,000 English words since Guaraní is mildly polysynthetic) and consists of personal narratives, fables, a theater play, and a Guaraní translation of The Little Prince (Saint-Exupéry 2005). Excluding the modal stem -katu 'possible', the corpus contained 133 occurrences of katu. Of these, 34 were occurrences of katu-ete (katu-very), translatable as 'always' or 'certainly', and 14 were occurrences of mbegué-katu (slow-katu) 'slowly'. These two expressions occur in a variety of positions in the sentence. 81 occurrences of katu did not have an apparent translation (as 'always', 'certainly', 'slowly', or something else) and 80 of these katu occurred in second position. Four occurrences of katu in the corpus did not fit any of these characterizations.

The empirical focus of this article is on the katu that does not have an appar- 
ent translation and is typically realized in second position. The hypothesis that this expression, which is analyzed as a (second-position) clitic, marks utterances as containing a contrastive topic arose from the observation that sentences with this clitic occur as part of discourses in which a contrast is implied between two or more entities, typically individuals. In (4), the contrast is between individuals and how many patties they ate; in (5), the contrast is between individuals and their work habits.

(4) [Sambo's father ate 35 mbeju (mandioka starch pattie), his mother ate 20]

$$
\begin{aligned}
& \text { ha Sámbo=katu ho’u } 54 \text { mbeju. } \\
& \text { and Sambo=CONTRAST A3.eat } 54 \text { mbeju } \\
& \text { 'and Sambo ate } 54 \text { mbeju.' }
\end{aligned}
$$

(5) [Doña Guapa was a hard-working woman. [...]]

I-ména=katu=ndaje tekoréi ruvicha.

B3-husband=CONTRAST=SAY low.life boss

'Her husband, on the other hand, was said to be the king of lowlifes.'

(K et al. 2005: 10f.)

To explore the hypothesis that the clitic =katu marks contrastive topic utterances, the next section introduces Büring's (2003) analysis of English contrastive topics.

\section{Büring (2003): Contrastive topic strategies}

Utterances with contrastive topics have been discussed extensively in the formal semantic/pragmatic literature (see e.g Büring 1997, 2003; Roberts 1998; Krifka 1999; Lee 1999; Constant 2008; Wagner 2008). This article introduces Büring's (2003) analysis since, as shown below, it can be adapted to account for $=k a t u$.

Büring assumes that in order for a discourse to be coherent, any utterance $U$ must be able to map onto a move in a $\mathrm{d}$ [iscourse]-tree (which is subject to wellformedness conditions). In particular, utterances with a contrastive topic and a focus "presuppose not just a question under discussion, but a possibly complex strategy of questions" (Roberts 1998: 39). In Büring 2003, this complex strategy of questions is given by $\llbracket \mathrm{U} \rrbracket^{c t}$, the contrastive topic value of an utterance $U$. Büring (2003) illustrates how this value is calculated using R's utterance in (1), Fred $d_{C T}$ ate the $B_{E A N S_{F}}$ (where the subscripts $C T$ and ${ }_{F}$ indicate which constituents are prosodically identified as the contrastive topic and the focus, respectively).

The first step is to form a question from R's utterance in (1) by replacing the focus of the utterance with a $w h$-word (and other necessary syntactic changes):

(6) What did Fred eat? 
The second step is to form a set of questions by replacing the contrastive topic with alternatives to it:

(7) What did Fred eat?, What did Mary eat?, What did Sam eat?, ...

This set of questions is the contrastive topic value of R's utterance in (1):

$\llbracket$ Fred $_{C T}$ ate the $\mathrm{BEANS}_{F} \rrbracket^{c t}=\left\{\left\{\mathrm{x}\right.\right.$ ate $\left.\left.\mathrm{y} \mid \mathrm{y} \in D_{e}\right\} \mid \mathrm{x} \in D_{e}\right\}$

Since Büring's calculation of the contrastive topic value depends on prosodic identification of the contrastive topic and the focus, different accent placements lead to different contrastive topic values. Thus, the contrastive topic value of R's utterance in (2) is a set of questions of the form "For all $y$, who ate $y$ ?":

(9) $\llbracket$ Fred $_{F}$ ate the BEANS $C T \rrbracket^{c t}=\left\{\left\{\mathrm{x}\right.\right.$ ate $\left.\left.\mathrm{y} \mid \mathrm{x} \in D_{e}\right\} \mid \mathrm{y} \in D_{e}\right\}$

In Büring's analysis, the contrastive topic value of an utterance determines the appropriateness conditions for that utterance. Büring (2003: 520) associates an utterance $U$ containing a contrastive topic with its appropriateness condition by requiring, through $\mathrm{CT}$-congruence in (10), that $U$ indicates a strategy around the move in the discourse tree onto which $U$ maps, with a strategy defined as in (11).

(10) CT-Congruence:

(Büring 2003: 520)

An utterance $U$ containing a contrastive topic can map onto a move $M_{U}$ within a d[iscourse]-tree $D$ only if $U$ indicates a strategy around $M_{U}$ in $D$.

(11) Strategy:

(Büring 2003: 520)

$U$ indicates a strategy around $M_{U}$ in $D$ iff there is a non-singleton set $Q^{\prime}$ of questions such that for each $Q \in Q^{\prime}$, (i) $Q$ is identical to or a sister of the question that immediately dominates $M_{U}$, and (ii) $\llbracket \mathrm{Q} \rrbracket^{o} \in \llbracket \mathrm{U} \rrbracket^{c t}$.

According to this analysis, R's utterance in (1) is acceptable only if it can map onto an assertion move $M_{U}$ in a d-tree in which there is a non-singleton set of questions $Q^{\prime}$ such that each question $Q$ in $Q^{\prime}$ is identical to or a sister of the question that immediately dominates $M_{U}$, i.e. identical to or a sister of the question What did Fred eat?, and if the ordinary semantic values of the questions in $Q$ are elements of the contrastive topic value of R's utterance. Thus, R's utterance in (1) is acceptable only in a discourse where questions of the form "What did $x$ eat?" are under discussion. By contrast, R's utterance in (2) is acceptable only in a discourse where questions of the form "Who ate $y$ ?" are under discussion.

\section{Hypothesis: =katu indicates a contrastive topic strategy}

This section explores the hypothesis that =katu does not contribute to the proffered content of the utterance in which it occurs, but that utterances with $=k a t u$ are felicitous in a discourse if and only if the utterance indicates a contrastive topic strategy. 
Contrastive topics in Paraguayan Guaraní discourse

\section{(12) Felicity condition of utterances with =katu (to be revised):}

An utterance $U$ of a sentence containing =katu is felicitous if and only if $U$ maps to a move $M_{U}$ within a d-tree $D$ such that $U$ indicates a contrastive topic strategy around $M_{U}$ in $D$, as defined in (11).

This analysis makes the following three predictions, which this section shows to be empirically correct: 1 . Naturally occurring examples with =katu suggest a contrastive topic strategy, 2. The contrastive topic strategy of such examples can be made explicit, and 3. Utterances with $=k a t u$ that are not part of a contrastive topic strategy are unacceptable. (See Constant 2011 for additional diagnostics.)

\subsection{Prediction \#1: Naturally occurring examples suggest a CT strategy}

The strategy of contrastive topic utterances in naturally occurring discourse is often not fully explicit since parts of the strategy, both question and answer moves, need not be linguistically realized but can be implicit (see e.g. Büring 2003: §5 for discussion). A first prediction of the analysis given in (12) is that if utterances with $=k a t u$ are only acceptable if they are part of a contrastive topic strategy, the discourse in which such utterances occur should suggest such a strategy. This prediction is borne out, as illustrated with (4).

(4) [Sambo's father ate 35 mbeju, his mother ate 20 mbeju]

$$
\begin{aligned}
& \text { ha Sámbo=katu ho’u } 54 \text { mbeju. } \\
& \text { and Sambo=CONTRAST A3.eat } 54 \text { mbeju } \\
& \text { 'and Sambo ate } 54 \text { mbeju.' }
\end{aligned}
$$

According to the analysis in (12), the utterance $U$ with $=k a t u$ in (4) is acceptable only if $U$ indicates a strategy around $M_{U}$ in $D$. Assuming that $S a m b o$ is the contrastive topic of $U$ and 54 is the focus (see section 6 for discussion), $U$ has the following contrastive topic value:

$$
\begin{aligned}
& \text { ['[Sambo }]_{C T}=\mathbf{k a t u} \text { ate }[54]_{F} \text { mbeju' } \rrbracket^{c t} \\
& =\left\{\left\{\mathrm{x} \text { ate y-many mbeju } \mid y \in D_{e}\right\} \mid x \in D_{e}\right\}
\end{aligned}
$$

Per Büring's analysis, $U$ indicates a strategy around $M_{U}$ in $D$ if and only if there is a non-singleton set $Q^{\prime}$ of questions such that for each $Q \in Q^{\prime}$, (i) $Q$ is identical to or a sister of the question that immediately dominates $M_{U}$, and (ii) $\llbracket \mathrm{Q} \rrbracket^{o} \in\{\{\mathrm{x}$ ate y-many mbeju $\left.\left.\mid y \in D_{e}\right\} \mid x \in D_{e}\right\}$. It is plausible to assume that the relevant set of questions $Q^{\prime}$ is $\{$ How many mbeju did Sambo's father eat?, How many mbeju did Sambo's mother eat?, How many mbeju did Sambo eat?\}. Since each of these questions is answered by an utterance in (4), and their ordinary semantic values are 
elements of the contrastive topic value in (13), the analysis correctly predicts that $=$ katu is acceptable in the last utterance in (4).

\subsection{Prediction \#2: The CT strategy can be made explicit}

The discussion in the previous section relied on me, a native speaker of German, identifying the contrastive topic strategy of a Guaraní utterance. That is, the discussion assumed that the organization and structure of discourse in German and Guaraní is similar enough for my judgments about discourse strategies to be shared by speakers of Guaraní. While this assumption may be a good null hypothesis, we can do better and show that native speakers of Guaraní also share the intuition that utterances with =katu indicate a contrastive topic strategy. Asking consultants directly whether utterances with $=k a t u$ indicate a contrastive topic strategy is not feasible. But the analysis in (12) predicts that if an utterance with $=k a t u$ indicates a contrastive topic strategy, native speakers of Guaraní should judge discourses in which the strategy is made explicit to be acceptable. This prediction is indeed borne out, as illustrated in (14), where speaker B's turns in B1, B2 and B3 constitute the original example in (4). The speakers I consulted judged this discourse, and others like it, to be acceptable.

(14) Conversation between A and B

A1: Mboy mbejú=pa ho’u máva? Mboý=pa ho’u Sámbo ru? how.many mbeju=QU A3.eat who how.many=QU A3.eat Sambo father 'Who ate how many mbeju? How many did Sambo's father eat?'

B1: Sámbo ru ho’u 35 mbeju. Sambo father A3.eat 35 mbeju

'Sambo's father ate 35 mbeju.'

A2: Mboý=pa ho'u Sámbo sy?

how.many $=$ QU A3.eat Sambo mother

'How many did Sambo's mother eat?'

B2: I-sy ho'u 20 mbejú-nte.

B3-mother A3.eat 20 mbeju-only

'Sambo's mother ate only 20 mbeju.'

A3: Mboý=pa ho'u Sámbo?

how.many=QU A3.eat Sambo

'How many did Sambo eat?'

B3: Sámbo=katu ho'u 54 mbeju. Sambo=CONTRAST A3.eat 54 mbeju

'Sambo ate 54 mbeju.' 
In sum, the analysis of utterances with =katu correctly predicts that discourses in which the contrastive topic strategy hypothesized to be indicated by the utterance is fully explicit are judged acceptable by native speakers of Guaraní.

\subsection{Prediction \#3: =katu utterances are unacceptable without a CT strategy}

A third prediction of the analysis in (12) is that utterances with $=k a t u$ should not be acceptable in discourses in which the utterance does not indicate a contrastive topic strategy. A first kind of example that shows that this is a correct prediction is one in which utterances with $=k a t u$ occur in contexts that are too impoverished to support a contrastive topic strategy. The utterance in (16), for example, is not acceptable in Context 1 in (15): in this context, two individuals are salient, namely Maria and Celina, but no contrastive topic strategy is apparent. Evidence that the unacceptability of (16) in Context 1 is indeed due to $=k a t u$ is that (16) without $=k a t u$ is acceptable in this context.

(15) Context 1: Maria runs into Celina in the supermarket and says:

Context 2: Maria runs into Celina in the supermarket and says Cheména ojoguáta servésa 'My husband is going to buy beer', and then:

Context 3: In the supermarket, Maria runs into Celina, who has a lot of beer in her cart. Maria says:

(16)(\#)Ché=katu a-joguá-ta kamby.

pron.S.1sg=CONTRAST A1sg-buy-PROSP milk

'I'm going to buy milk.'

By contrast, (16) is acceptable in Contexts 2 and 3: in the former, a contrastive topic strategy is made available by prior linguistic context (i.e. the strategy is strongly familiar, Roberts 2003); in the latter, the strategy is salient in the utterance context (i.e. it is weakly familiar). Thus, whereas the felicity condition $=k a t u$ imposes on context is not satisfied in Context 1, it is satisfied in Contexts 2 and 3.

The second kind of example that shows that utterances with $=k a t u$ are not acceptable in discourses which do not support a contrastive topic strategy are discourses in which the explicit question and answer moves do not form a contrastive topic strategy. Consider the example in (17).

(17) A: Tell me about your friends.

B: \#Juan o-nasẽ Alemánia-pe ha Pédro=katu iñ-aka-rangue sa'yju. Juan A3-born Germany-in and Pedro=contrast B3-head-hair yellow 'Juan was born in Germany and Pedro is blonde.' 
Without $=k a t u,(17 \mathrm{~B})$ was judged acceptable by my consultants; the utterance became unacceptable (or at least worse) with the addition of $=k a t u$. Under the assumption that Pedro is the contrastive topic of the utterance $U$ of the clause that contains $=k a t u$, and that $s a^{\prime} y j u$ 'yellow' is the focus, this utterance answers the question 'What color hair does Pedro have?'. The contrastive topic value of $U$ is:

$$
\begin{aligned}
& \llbracket[\text { [Pedro }]_{C T}=\mathbf{k a t u} \text { has }[\text { blonde }]_{F} \text { hair' } \rrbracket^{c t} \\
& =\left\{\left\{\mathrm{x} \text { has y-colored hair } \mid y \in D_{\langle e, t\rangle}\right\} \mid x \in D_{e}\right\}
\end{aligned}
$$

According to (12), the discourse in (17) is felicitous if and only if the questions that the two atomic clauses in (17) answer are elements of the contrastive topic value of $U$. This is the case for the question 'What color hair does Pedro have?', but not for 'Where was Juan born?', which is the question answered by the first atomic clause. The analysis in (12) thus correctly predicts that (17) is unacceptable since a contrastive topic strategy cannot be established for this discourse.

Note, however, that (17) is predicted to be acceptable if we assume that the type of question that both clauses in (17) address is 'What properties does $X$ have?', where $X$ is either Pedro or Juan. A discussion of why the two clauses cannot be construed as answering this type of question is left to future research.

\subsection{Interim summary}

This section empirically motivated an analysis of =katu as requiring, similar to (prosodic, morphological, syntactic) contrastive topic markers of other languages, that an utterance of the sentence in which it occurs is part of a contrastive topic strategy. The next two sections discuss differences between contrastive topic utterances in Guaraní and other languages.

\section{$5=k a t u$ requires an antecedent proposition}

The clitic $=k a t u$ differs in its distribution from contrastive topic markers in other languages. In English, for example, an utterance with contrastive topic prosody is acceptable in a context like (19), and such examples are also acceptable in Japanese, Korean and German (Kuno 1973: 47; Lee 1999: 322f.; Büring 1997).

(19) [No prior discourse, at least on a related subject]

A: When are you going to China?

B: I'm going to [China $]_{C T}$ in $[\text { April }]_{F}$. (adapted from Roberts 1998: 38)

The Guaraní variant of (19B) given in (20), however, is unacceptable. The utterance is acceptable without $=k a t u$, showing that it is the meaning of $=k a t u$ that results in the unacceptability of (20). 
Contrastive topics in Paraguayan Guaraní discourse

$$
\begin{aligned}
& \text { B: \# Chína-pe=katu a-há-ta Abríl-pe. } \\
& \text { China-to=CONTRAST A1-go-PROSP April-in } \\
& \text { (Intended: I'm going to China in April.) }
\end{aligned}
$$

Another illustration of distributional differences between $=k a t u$ and contrastive topic markers in other languages is given in examples (21) and (22), both of which are variants of (5), repeated here for convenience.

(5) $\tilde{\mathrm{Na}}$ Guápa=ndaje=ko kuñakarai katupyry. [...]

Doña Guapa $=$ SAY $=$ EMPH woman clever

I-ména=katu=ndaje tekoréi ruvicha.

B3-husband=CONTRAST=SAY low.life boss

'Doña Guapa was a clever woman. [...] Her husband, on the other hand, was said to be the king of lowlifes.

(K et al. 2005: 10f.)

The variant of (5) in (21), where =katu occurs in the first clause, is unacceptable (regardless of whether or not $=k a t u$ is realized in the second clause). By contrast, both clauses in the English or Germans translations of the example could be uttered with contrastive topic prosody.

$$
\begin{aligned}
& \text { \#Ña Guápa=katu=ndaje=ko kuñakarai katupyry... } \\
& \text { Doña Guapa }=\text { CONTRAST }=\text { SAY }=\text { EMPH woman clever }
\end{aligned}
$$

(Intended: Doña Guapa was a clever woman...)

(21) is unacceptable even in a context in which the two individuals to be contrasted have already been introduced, as in response to (22).

$$
\begin{aligned}
& \text { E-mo-ñe'ẽ chéve Doña Guapa ha i-ména-re. } \\
& \text { A2sg-CAUS-say pron.O.1sg Doña Guapa and B3-husband-of }
\end{aligned}
$$

'Tell me about Doña Guapa and her husband.'

These examples show that =katu has a more restricted distribution than contrastive topic markers in other languages. In particular, =katu requires not only that the utterance in which it occurs is part of a contrastive topic strategy, but that there is an antecedent proposition. This antecedent proposition need not be strongly familiar, as shown by the fact that (16) is acceptable in Context 3. Which antecedent proposition is suitable as an antecedent for =katu depends on the particular contrastive topic strategy that the utterance of the sentence in which =katu occurs in is part of. This additional requirement is formally captured in condition (ii) of (23), which specifies that the utterance of the sentence in which =katu occurs is not the first answer move of the contrastive topic strategy: 


\section{(23) Felicity condition of utterances with =katu (final version):}

An utterance $U$ of a sentence containing =katu is felicitous if and only if (i) $U$ maps to a move $M_{U}$ within a d-tree $D$ such that $U$ indicates a contrastive topic strategy around $M_{U}$ in $D$, as defined in (11), and (ii) there is an answer move $M_{U}{ }^{\prime}$ that is a left sister to move $M_{U}$.

Thus, the realization of contrastive topic strategies may very well be a universal property of human language. Support for this proposal comes from the fact that contrastive topic strategies have been attested across a typologically diverse range of languages. At the same time, the findings presented here suggest that there is crosslinguistic variation in the particular requirements that a contrastive topic marker imposes on the discourse in which contrastive topic utterances are realized.

\section{Grammatical marking of contrastive topics}

So far, the discussion of utterances of sentences containing =katu has stipulated particular contrastive topic values for these utterances, and nothing has been said about how the contrastive topic values of Guaraní utterances are calculated. This section provides evidence that contrastive topics are not grammatically marked in Guaraní, unlike contrastive topics in other languages, and proposes that a confluence of factors determines the contrastive topic value of utterances with $=k a t u$.

\subsection{Contrastive topic-marking across languages}

Recall from section 3 that Büring's (2003) calculation of the contrastive topic value of English utterances relies on both the contrastive topic and the focus of the utterance being prosodically identified. In other languages, too, the contrastive topic of an utterance is (assumed to be) grammatically marked, and sometimes also the focus. In German, prosody is taken to indicate the contrastive topic and the focus, respectively (e.g. Büring 1997; but see Wagner 2008). In Hungarian, a contrastive topic is typically realized in a position preceding the focus and the verb (see e.g. Szabolcsi 1981). And, in Korean and Japanese, the contrastive topic of an utterance is marked with a suffix (see e.g. Kuno 1973; Lee 1999), e.g. -nun in Korean:

(24) Context: as in (19)

B: na [cungkuk-e-nun] sa-wol-e ka

$$
\text { I China-to-CT April-in go }
$$

'I'm going to China in April.'

(adapted from Lee 1999: 322)

The next two sections show that, in Guaraní, neither word order nor prosody alone determine the contrastive topic or the focus of an utterance with $=k a t u$. 
Contrastive topics in Paraguayan Guaraní discourse

\subsection{Word order}

The examples in (25) illustrate that word order does not determine the contrastive topic and the focus of an utterance of a sentence with =katu (see also Constant 2011 for Mandarin). Both discourses in (25) answer A's question of who was born where. In the person-by-person strategy pursued in (25a), the subject of C1's utterance $(B o b)$ is the contrastive topic; in the country-by-country strategy pursued in (25b), Estádos Unído 'USA' in C2's utterance is the contrastive topic. Since C1 and C2 are string-identical, with $=k a t u$ cliticizing to the subject noun phrase $B o b$, these examples show that word order does not identify the contrastive topic and the focus of Guaraní utterances with =katu.

(25) Context: At a meeting of ten strangers from all over the world.

A: Who was born where?

a. B1: Juana was born in Argentina. Where was Bob born?

C1: $\quad[\mathrm{Bób}]_{C T}=\mathbf{k a t u}$ o-nasẽ [Estádo Unído] $]_{F}$-pe. $\mathrm{Bob}=\mathrm{CONTRAST}$ A3-born States United-in

'Bob was born in the USA.'

b. B2: Juana was born in Argentina. Who was born in the USA?

C2: $[\mathrm{Bób}]_{F}=\mathbf{k a t u}$ o-nasẽ $[\text { Estádo Unído }]_{C T}$-pe. Bob=CONTRAST A3-born States United-in 'Bob was born in the USA.'

In naturally occurring discourse, $=k a t u$ tends to cliticize to the contrastive topic, which suggests that word order may provide a clue about the contrastive topic of the utterances with =katu (see section 6.4 for discussion). Data like (25) show, however, that word order cannot be assumed to determine the contrastive topic.

\subsection{Prosody}

To explore the hypothesis that the contrastive topic strategy of a Guaraní utterance with $=k a t u$ is prosodically indicated, I conducted a perception experiment with native speakers of Guaraní in Paraguay. This experiment required listeners to identify which of two lexically identical answers with =katu was the preferred response to a short utterance that sets up a contrastive topic strategy with either the subject or the object of the answer as the contrastive topic. Given an utterance that establishes the subject (the object) of the answer as a contrastive topic, we expect that listeners will chose the response whose prosodic cues identify the subject (the object) as the contrastive topic. 
Judith Tonhauser

\subsubsection{Participants}

Fourteen adults (five male), recruited in San Lorenzo, Paraguay, voluntarily took part in the experiment. They were native speakers of Guaraní and Spanish, and had no known hearing problems.

\subsubsection{Stimulus materials}

Ten pairs of discourses were constructed. The two discourses in each of the ten pairs consisted of a context utterance (A), which was an indicative sentence and a question, and a response sentence (B) that contained =katu. In each pair of discourses, the response sentences were string-identical. (26) is a sample pair: the response sentence B in (26a) is string-identical to that in (26b).

a. A: Pédro ha'e karniséro. Mba'é-pe=pa o-mba'apo Paméla?

Pedro COP butcher what-at=QU A3-work Pamela

'Pedro is a butcher. What's Pamela's job?'

B: Paméla=katu almasenéra.

Pamela=CONTRAST store.keeper

'Pamela is a store keeper.'

b. A: Pédro ha'e karniséro. Máva=pa almasenéra?

Pedro COP butcher who=QU store.keeper

'Pedro is a butcher. Who is a store keeper?'

B: Paméla=katu almasenéra.

Pamela=CONTRAST store.keeper

'Pamela is a store keeper.'

The ten response sentences containing $=k a t u$ realized a sentence-initial subject, to which $=k a t u$ cliticized ( $\mathrm{B}$ in (26a) and (26b) is one such response sentence). In six of the response sentences, the subject was followed by a transitive verb and a (prepositional) object noun (as in (25)). In two of the response sentences, the subject was followed by an object noun as part of a copula sentence (as in (26)), and in two of the response sentences the subject was followed by an intransitive verb. Each discourse pair was constructed such that the subject was the contrastive topic of the response sentence in the first member of the pair (i.e. Paméla in (26a)) and a non-subject expression was the contrastive topic of the response sentence in the second member of the pair: in response sentences with an object, the object was the contrastive topic in the second member of the pair (i.e. almasenéra 'store keeper' in (26b)), and in response sentences with intransitive verbs, the intransitive verb was the contrastive topic in the second member of the pair. 
A list was constructed with the twenty discourses in a pseudo-randomized order. Two native speakers of Guaraní who were fluent readers of the language read the discourses. Both were given a copy of the discourses in advance of the recording session to allow them to familiarize themselves with the materials. The first speaker read the context utterances A (henceforth, "speaker A"). This speaker was recorded in a quiet location with a table-mounted ATR20 microphone; a digital stereo recording with a sampling rate of $44,1 \mathrm{kHz}$ was made using an Edirol R09 compact flash recorder. The second speaker listened to speaker A's utterances at a later time in a quiet location in her house and responded with the corresponding response sentences B. This speaker (henceforth, "speaker B") was recorded using the built-in microphone in a MacBook Air computer using the Praat software. For this speaker, a digital mono recording with a sampling rate of $44,1 \mathrm{kHz}$ was made.

The stimulus materials for the ten trials of the perception experiment were extracted from these recordings. Each of the ten experiment stimuli consisted of a sequence of a context utterance (by speaker A) followed by the two string-identical response sentences of that discourse pair (uttered by speaker B). The second experiment stimulus, for example, consisted of A's utterance in (26b) followed by B's responses in (26a) and (26b). Thus, in each trial, one of the two response utterances was given in response to A's context utterance in the stimulus (the "matching" response, e.g. B's utterance in (26b), in the second experiment stimulus), whereas the other response utterance was produced in response to A's context utterance in the other member of the discourse pair (the "non-matching" response, e.g. B's utterance in (26a), in the second experiment stimulus).

In half of the ten trials, A's context utterance set up a contrastive topic strategy in which the subject was the contrastive topic (as in (26a)); in the other five, A's utterance set up an object contrastive topic strategy (as in (26b)). (Thus, there was no stimulus in which A's utterance set up a verb contrastive topic strategy.) In approximately half of the subject contrastive trials and half of the object contrastive trials, the first response utterance was the matching response.

The ten trials were presented in one pseudo-randomized order to half of the participants, and in the reverse order to the other half. ${ }^{2}$

\subsubsection{Procedure}

The participants were tested individually in a quiet location. The presentation of the stimulus materials was controlled on a MacBook Air laptop. The trials were presented one at a time over the built-in speakers of the laptop. The listeners were asked to identify whether B's first or B's second utterance sounded better in re-

2 See the online appendix at http://www.ling.osu.edu/ judith/katu-stimuli.pdf for the full set of trials. 


\begin{tabular}{ccccccccccc}
\hline & \multicolumn{11}{c}{ Trial \# } \\
& $\mathbf{\# 1}$ & $\mathbf{\# 2}$ & $\mathbf{\# 3}$ & $\mathbf{\# 4}$ & $\mathbf{\# 5}$ & $\mathbf{\# 6}$ & $\mathbf{\# 7}$ & $\mathbf{\# 8}$ & $\mathbf{\# 9}$ & $\mathbf{\# 1 0}$ \\
Matching responses & 7 & 6 & 10 & 10 & 9 & 3 & 9 & 8 & 6 & 9
\end{tabular}

Table 1 Number of matching responses

sponse to A's utterance. The listeners responded verbally in Spanish, and their responses were coded. Participants were permitted to listen to each trial as many times as they wanted before responding, but usually only listened once to each trial.

\subsubsection{Results}

Contrary to expectation, listeners did not chose the matching utterance more often than the non-matching one (77 out of 140 total trials, $55 \%$ overall; see Table 1; the subject contrastive trials are \#3, \#4, \#6, \#8, \#9). While the number of matching responses for most trials was at chance, there were some trials for which there was higher agreement among listeners as to the more appropriate response. For example, listeners preferred the matching (subject contrastive) response utterance for trials \#3 and \#4 and the non-matching (object contrastive) response utterance for trial \#6. Whether these preferences can be attributed to prosodic properties of the respective utterances that are relevant to the determination of their contrastive topic values is a question for future research.

\subsubsection{Discussion}

The results of the perception experiment suggest that the prosody of utterances of sentences containing =katu does not determine the contrastive topic strategy of the utterance. These findings dovetail with the results of Clopper \& Tonhauser (2011, 2012, in print), who show that focus is prosodically marked in Guaraní, but that this marking is probabilistic, not categorical.

Since $=k a t u$ also occurs in written texts (which do not contain any prosodic information), these results show that the calculation of the contrastive topic value of an utterance of a sentence with =katu cannot rely on prosody alone. See e.g. Krifka 1999 for a similar proposal for German contrastive topic utterances.

\subsection{Determining the CT value of utterances with $=k a t u$}

This section has shown that the contrastive topic and focus of an utterance with $=k a t u$ is not determined grammatically. As a consequence, a formal analysis cannot 
assume that the contrastive topic value of such utterances can be calculated from their structures or semantic translations. Instead, utterances like (4) do not give rise to one particular contrastive topic value, but are instead compatible with several different ones. Three are given for (4) in (27):

【'Sambo=katu ate 54 mbeju' $\rrbracket^{c t}$

a. $\llbracket{ }^{\prime} \operatorname{Sambo}_{C T}=\mathbf{k a t u}$ ate $[54]_{F}$ mbeju' $\rrbracket^{c t}$ $=\left\{\left\{\mathrm{x}\right.\right.$ ate $\mathrm{y}$-many mbeju $\left.\left.\mid \mathrm{y} \in D_{e}\right\} \mid \mathrm{x} \in D_{e}\right\}$

b. $\llbracket{ }^{\prime} \operatorname{Sambo}_{F}=\mathbf{k a t u}$ ate $[54]_{C T}$ mbeju' $]^{c t}$ $=\left\{\left\{\mathrm{x}\right.\right.$ ate $\mathrm{y}$-many mbeju $\left.\left.\mid \mathrm{x} \in D_{e}\right\} \mid \mathrm{y} \in D_{e}\right\}$

c. $\llbracket$ 'Sambo $_{C T}=\mathbf{k a t u}$ ate $[54 \mathrm{mbeju}]_{F}{ }^{\prime} \rrbracket^{c t}$

$$
=\left\{\left\{\mathrm{x} \text { ate } \mathrm{y} \mid \mathrm{y} \in D_{e}\right\} \mid \mathrm{x} \in D_{e}\right\}
$$

I propose that the contrastive topic value of an utterance with =katu is not determined grammatically but depends on a confluence of several factors. First, although the prosody of the utterance does not determine the contrastive topic or the focus of the utterance, it may very well provide clues as to which expression plays which role in the larger discourse context (see also Clopper \& Tonhauser in print). Second, word order in Guaraní is discourse-sensitive (Velázquez-Castillo 1995, 1996; Tonhauser \& Colijn 2010): both hearer-new subjects, which are less likely to be contrastive topics, and topical objects, which are more likely to be contrastive topics than foci, more often occur after the verb than before it. Third, the context of the utterance provides information as to which expressions denote topics, and which denote hearer-new entities. And, finally, world knowledge may play a role in determining the contrastive topic value, as also acknowledged by Büring: For example, the contrastive topic value in $(27 \mathrm{c})$, a set of questions of the form "For each number $y$, who ate that many mbeju?", may simply be "a pointless and ineffective strategy to approach answering the super-question” (Büring 2003: 530).

\section{Conclusion}

This article empirically motivated that the Guaraní clitic =katu is a contrastive topic marker à la Büring (2003). The analysis of =katu suggests that whereas indicating contrastive topic strategies may be a language-universal, languages differ not only in the grammatical means by which such strategies are indicated, but also in the particular requirements contrastive topic markers impose on context.

\section{References}

Bossong, Georg. 1983. Über einige Besonderheiten der Tupi-Guarani-Sprachen. Khipu: Revista bilingüe de cultura sobre América Latina 11. 39-44. 
Büring, Daniel. 1997. The Meaning of Topic and Focus - The 59th Street Bridge Accent. London: Routhledge.

Büring, Daniel. 2003. On D-trees, beans and B-accents. Linguistics and Philosophy 26. 511-545.

Clopper, Cynthia G. \& Judith Tonhauser. 2011. On the prosodic coding of focus in Paraguayan Guaraní. In Proceedings of the 28th West Coast Conference on Formal Linguistics, 249-257. Somerville, MA: Cascadilla Proceedings Project.

Clopper, Cynthia G. \& Judith Tonhauser. 2012. Focus projection in Paraguayan Guaraní noun phrases. Talk given at the 2012 Workshop on the Structure and Constituency of Languages of the Americas, University of Chicago, March 9.

Clopper, Cynthia G. \& Judith Tonhauser. in print. The prosody of focus in Paraguayan Guaraní. International Journal of American Linguistics.

Constant, Noah. 2008. English Rise-Fall-Rise: A Study in the Semantics and Pragmatics of Intonation. UCSC MA thesis.

Constant, Noah. 2011. On the independence of Mandarin aspectual and contrastive sentence-final ne. In Proceedings of North American Conference on Chinese Linguistics, vol. 23, 15-29.

von Fintel, Kai \& Lisa Matthewson. 2008. Universals in semantics. The Linguistic Review 25. 139-201.

Ginzburg, Jonathan. 1995. Resolving questions I, II. Linguistics \& Philosophy 18. 459-527, 567-609.

Gregores, Emma \& Jorge A. Suárez. 1967. A Description of Colloquial Guaraní. The Hague: Mouton de Gruyter.

Guasch, Antonio \& Diego Ortiz. 2001. Diccionario castellano-guaraní, guaranícastellano. Asunción, Paraguay: CEPAG.

Jackendoff, Ray. 1972. Semantic Interpretation in Generative Grammar. Cambridge, MA: MIT Press.

Kiss, Katalin É. 1987. Configurationality in Hungarian. Dordrecht: Reidel.

Krifka, Manfred. 1999. Additive particles under stress. In Proceedings of Semantics and Linguistic Theory 8, 111-128. Cornell: CLC Publications.

Krivoshein de Canese, Natalia, Carlos Martinez Gamba \& Feliciano Acosta Alcaraz (eds.). 2005. Tetãgua remimombe’u: Cuentos populares paraguayos. Asunción, Paraguay: Servilibro.

Kuno, Susumu. 1973. The Structure of the Japanese Language. Cambridge, MA: MIT Press.

Lee, Chungmin. 1999. Contrastive topic: A locus of the interface. Evidence from English and Korean. In K. Turner (ed.), The Semantics/Pragmatics Interface from Different Points of View, 317-342. Amsterdam: Elsevier.

Lustig, Wolf. 1996. Interaktives Wörterbuch Guarani. http://www.romanistik.unimainz.de/cgi-bin/guarani/Woerterbuch. 
Contrastive topics in Paraguayan Guaraní discourse

Ministerio de Educación y Cultura. 2004. La educación bilingüe en la reforma educativa Paraguaya. Available online at www.escuelavivamec.edu.py/investigaciones/60.pdf, last checked 08/30/08.

Roberts, Craige. 1998. Information Structure in Discourse: Toward an Integrated Formal Theory of Pragmatics. Updated from 1996 publication in OSU Working Papers in Linguistics, vol. 49.

Roberts, Craige. 2003. Uniqueness in definite noun phrases. Linguistics and Philosophy 26(3). 287-350.

Rooth, Mats. 1992. A theory of focus interpretation. Natural Language Semantics 1. 75-116.

Saint-Exupéry, Antoine de. 1946. The Little Prince. Paris: Editions Gallimard.

Saint-Exupéry, Antoine de. 2005. Mitãmi (The Little Prince). Asunción, Paraguay: Espectrograf, Artes Gráficas. Guaraní translation of Saint-Exupéry (1946) by De Las Nieves Domínguez and Enrique Chamorro.

Szabolcsi, Anna. 1981. The semantics of topic-focus articulation. In J.A.G. Groenendijk, T.M.V. Janssen \& M.B.J. Stokhof (eds.), Formal Methods in the Study of Language, 513-541. Amsterdam: Mathematisch Centrum.

Tonhauser, Judith \& Erika Colijn. 2010. Word order in Paraguayan Guaraní. International Journal of American Linguistics 76. 255-288.

Velázquez-Castillo, Maura. 1995. Noun incorporation and object placement in discourse: The case of Guaraní. In Pamela Downing \& Mickey Noonan (eds.), Word Order in Discourse, 555-579. Amsterdam/Philadelphia: John Benjamins.

Velázquez-Castillo, Maura. 1996. The Grammar of Possession: Inalienability, Incorporation and Possessor Ascension in Guaraní. Amsterdam: John Benjamins.

Velázquez-Castillo, Maura. 2004. Guaraní (Tupí-Guaraní). In G.E. Booij, C. Lehmann, J. Mugdan \& S. Skopeteas (eds.), Morphology: An International Handbook on Inflection and Word-Formation, vol. 2, 1421-1432. Berlin: Walter de Gruyter.

Wagner, Michael. 2008. A compositional analysis of contrastive topics. In Proceedings of North Eastern Linguistic Society 38, 415-428.

Zimmermann, Malte. 2011. Discourse particles. In Paul Portner, Claudia Maienborn \& Klaus von Heusinger (eds.), Handbook of Semantics, 2011-2038. Berlin: Mouton de Gruyter.

Judith Tonhauser

222 Oxley Hall, 1712 Neil Ave

Columbus, $\mathrm{OH} 43210$

judith@ling.osu.edu 